Article

\title{
Pyrolysis Products Distribution of Enzymatic Hydrolysis Lignin with/without Steam Explosion Treatment by Py-GC/MS
}

\author{
Yuguo Dong, Xinyu Lu, Chengjuan Hu, Liang Li, Qixiang Hu, Dandan Wang, Chaozhong Xu and \\ Xiaoli Gu *(D) \\ Co-Innovation Center for Efficient Processing and Utilization of Forest Products, College of Chemical \\ Engineering, Nanjing Forestry University, Nanjing 210037, China; dongyuguo99@outlook.com (Y.D.); \\ njfulxy@outlook.com (X.L.); hcj180203406@hotemail.com (C.H.); liliang250035@gmail.com (L.L.); \\ hu_qixiang@outlook.com (Q.H.); wdd8413709@outlook.com (D.W.); xucz@njfu.edu.cn (C.X.) \\ * Correspondence: guxiaoli@njfu.edu.cn; Tel.: +86-25-8542-7624
}

Received: 15 January 2020; Accepted: 1 February 2020; Published: 5 February 2020

\begin{abstract}
This paper investigated the pyrolytic behaviors of enzymatic hydrolysis lignin (EHL) and EHL treated with steam explosion (EHL-SE) by pyrolysis-gas chromatography/mass spectrometer (Py-GC/MS). It was shown that the main component of the pyrolysis products was phenolic compounds, including G-type, H-type, S-type, and C-type phenols. With different treatment methods, the proportion of units in phenolic products had changed significantly. Meanwhile, proximate, elemental, and FTIR analysis of both lignin substrates were also carried out for a further understanding of the lignin structure and composition with or without steam explosion treatment. FTIR result showed that, after steam explosion treatment, the fundamental structural framework of the lignin substrate was almost unchangeable, but the content of lignin constituent units, e.g., hydroxyl group and alkyl group, evidently changed. It was noticeable that 2-methoxy-4-vinylphenol with $11 \%$ relative content was the most predominant pyrolytic product for lignin after steam explosion treatment. Combined with the above analysis, the structural change and pyrolysis product distribution of EHL with or without steam explosion treatment could be better understood, providing more support for the multi-functional utilization of lignin.
\end{abstract}

Keywords: enzymatic hydrolysis lignin; steam explosion; phenolic compounds; Py-GC/MS

\section{Introduction}

As a natural aromatic polymer, lignin is one of the main components of lignocellulosic biomass in nature, which accounts for about 15\%-35\% of dry biomass [1-3]. Lignin is a three-dimensional, crosslinked and highly branched copolymer, which is derived from the random polymerization of three phenylpropane monomers, containing guaiacol $(\mathrm{G})$, syringyl $(\mathrm{S})$ and p-hydroxyphenyl $(\mathrm{H})[4,5]$. These aromatic monomers among lignin are mainly composed of $\mathrm{C}-\mathrm{O}-\mathrm{C}(\alpha-\mathrm{O}-4, \beta-\mathrm{O}-4,5-\mathrm{O}-4)$ and C-C (5-5, $\beta-1, \beta-5)$ bonds [6,7].

Currently, more than $60 \%$ of lignin resources are applied for low-grade boiler fuels for heating and power supply. Due to the aromatic nature of lignin, it is also known as a promising biomass resource for the preparation of bio-oil [8]. Bio-oil is transportable liquid with a high-energy content, which can be applied to subsequent biofuels and high value-added chemicals.

As one of the promising thermal approaches, pyrolysis could be applied to convert cheap, local, and abundant lignocellulosic biomass into energy [9]. It plays an important role in the thermochemical conversion of biomass to bioenergy. In order to obtain a deeper understanding of the complex structure of biomass, a pyrolyzer, coupled with gas chromatography/mass spectrometer (Py-GC/MS), has been 
widely used in recent decades [10-12]. Rich information about degradation products that can be obtained from specific spectra, which is advantageous in understanding the structure during biomass decomposition. The limitation of isothermal pyrolysis under constant conditions is that degradation products released from substrate pyrolysis cannot be separated. Py-GC/MS is an effective tool for qualitative and quantitative real-time analysis and the detection of each organic component in volatiles with the advantages of convenient detection and high sensitivity, which can easily identify complex organic compounds $[13,14]$. Therefore, Py-GC/MS could be widely employed to determine the effect of the reaction temperature on distribution and the content of pyrolysis products $[15,16]$. It was reported that guaiacol $(\mathrm{G})$, p-hydroxyphenol $(\mathrm{H})$, dimethoxy-phenol $(\mathrm{S})$ are the three most abundant phenols in bio-oil [17-21].

While a lot of research has been carried out on the pyrolysis of lignin, few have focused on product distribution of enzymatic hydrolysis lignin (EHL) with or without steam explosion treatment. The main purpose of this paper is to explore the pyrolysis behavior of EHL (with or without steam explosion treatment) by utilizing Py-GC/MS, and to compare the difference between the product distributions of the two lignin substrates. This work will also help to understand the impact of steam explosion on pyrolysis behavior of EHL by kinetic analysis.

\section{Results and Discussion}

The FTIR results of EHL and EHL treated with steam explosion (EHL-SE) were shown in Figure 1. According to other works (see Table 1) [22-26], peaks at $3500-3200 \mathrm{~cm}^{-1}$ is $\mathrm{O}-\mathrm{H}$ stretching vibration. After steam explosion treatment, the peak signal of $\mathrm{O}-\mathrm{H}$ is significantly reduced. The possible reason is that steam explosion treatment method is accompanied by the detachment of some hydroxyl functional groups. After that, peaks at $3000-2842 \mathrm{~cm}^{-1}$ express $\mathrm{C}-\mathrm{H}$ stretching in methyl and methylene groups. As can be seen from Figure 1, alkyl content of EHL-SE is significantly less than EHL, indicating that steam explosion treatment can remove most of alkyl component of lignin. Meanwhile, $\mathrm{C}-\mathrm{H}$ stretching vibration $-\mathrm{CH}_{3}$ and $-\mathrm{CH}_{2}-$ ) can be also detected at $1470-1445 \mathrm{~cm}^{-1}$. The peak intensity of alkyl in EHL-SE is shown to still be lower than EHL.

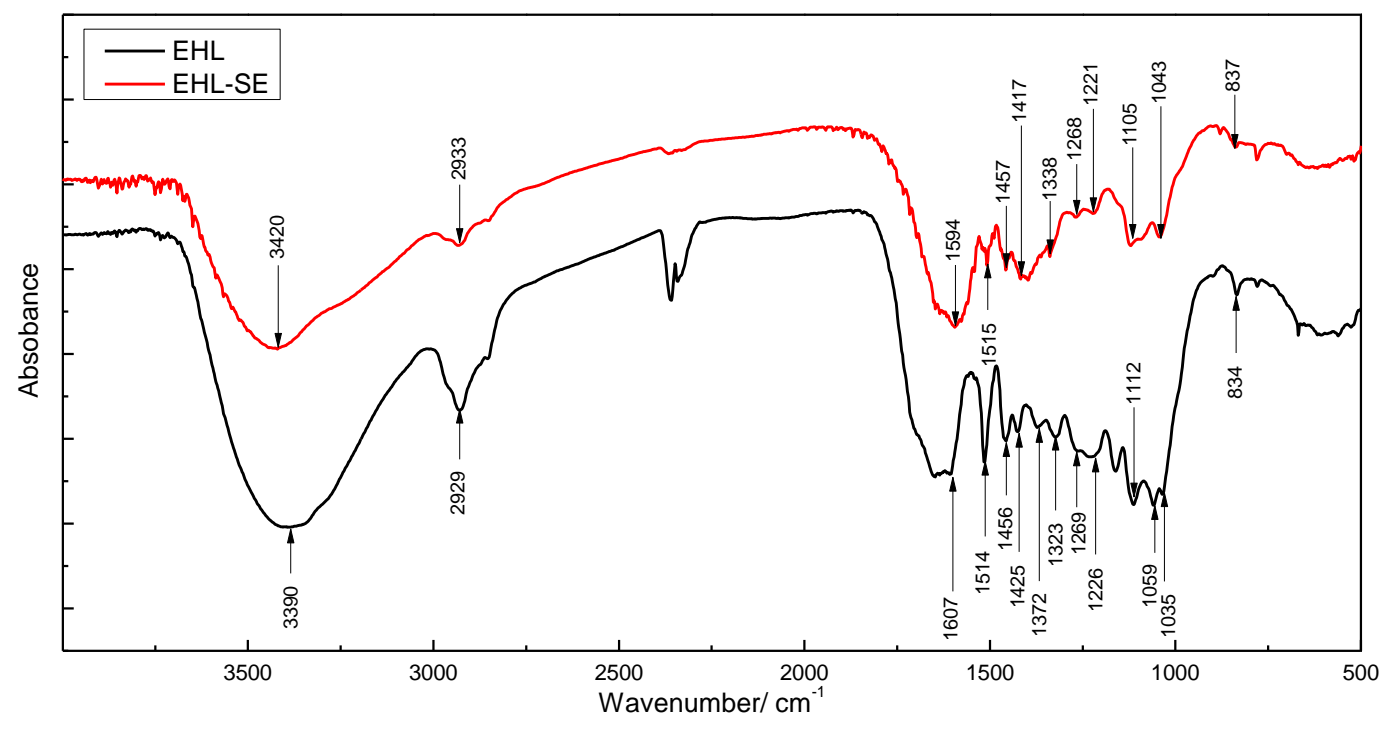

Figure 1. FTIR spectra of enzymatic hydrolysis lignin (EHL) and EHL treated with steam explosion (EHL-SE). 
Table 1. Specific FT-IR spectral of EHL and EHL-SE.

\begin{tabular}{|c|c|c|c|c|}
\hline \multirow[t]{2}{*}{ No. } & \multirow[t]{2}{*}{$\begin{array}{l}\text { Absorption Range } \\
\left(\mathrm{cm}^{-1}\right)\end{array}$} & \multirow[t]{2}{*}{ Characteristic Groups } & \multicolumn{2}{|c|}{ Relative Absorbance } \\
\hline & & & EHL & EHL-SE \\
\hline 1 & $3500-3200$ & $\mathrm{O}-\mathrm{H}$ stretching & 3390 & 3420 \\
\hline 2 & $3000-2842$ & $\mathrm{C}-\mathrm{H}$ stretch in methyl and methylene group & 2929 & 2933 \\
\hline 3 & $1615-1600$ & Aromatic skeletal vibrations & 1607 & 1594 \\
\hline 4 & $1515-1505$ & $\mathrm{C}=\mathrm{C}$ stretching in aromatic rings & 1514 & 1515 \\
\hline 5 & $1470-1445$ & $\mathrm{C}-\mathrm{H}$ bonds in hydrocarbons $\left(-\mathrm{CH}_{3}\right.$ and $\left.-\mathrm{CH}_{2}-\right)$ & 1456 & 1457 \\
\hline 6 & $1430-1422$ & $\begin{array}{l}\text { Aromatic skeleton vibrations combined with } \mathrm{C}-\mathrm{H} \text { in } \\
\text { plane deformations }\end{array}$ & 1425 & 1417 \\
\hline 7 & $1375-1330$ & S ring & 1372,1323 & 1338 \\
\hline 8 & $1233-1214$ & $\mathrm{C}-\mathrm{O}$ stretching in $\mathrm{S}$ rings & 1226 & 1221 \\
\hline 9 & $1270-1260$ & $\mathrm{G}$ ring $+\mathrm{C}-\mathrm{O}$ stretching in $\mathrm{G}$ rings & 1269 & 1268 \\
\hline 10 & 1110 & Aromatic $\mathrm{C} \mathrm{H}$ deformation of $\mathrm{S}$ rings & 1112 & 1105 \\
\hline 11 & $1035-1030$ & $\mathrm{C}-\mathrm{O}$ deformation in primary alcohol and aliphatic ether & 1059,1035 & 1043 \\
\hline 12 & $835-834$ & $\mathrm{C}-\mathrm{H}$ out of plane in $\mathrm{S}$ units (positions 2 and 6 ) & 834 & 837 \\
\hline
\end{tabular}

Afterwards, stretching vibrations at $1615-1600 \mathrm{~cm}^{-1}, 1515-1505 \mathrm{~cm}^{-1}$ and $1430-1422 \mathrm{~cm}^{-1}$ are attributed to aromatic skeletal vibrations and aromatic skeleton vibrations combined with $\mathrm{C}-\mathrm{H}$ in plane deformations, which belong to the basic vibration peaks of lignin. Hereafter, peaks at $1375-1330 \mathrm{~cm}^{-1}$, $1233-1214 \mathrm{~cm}^{-1}, 1110 \mathrm{~cm}^{-1}$ and $835-834 \mathrm{~cm}^{-1}$ are characterized as $\mathrm{S}$ rings and $\mathrm{C}-\mathrm{O}$ stretching in $\mathrm{S}$ rings, and peaks at $1270-1260 \mathrm{~cm}^{-1}$ are designated to be $\mathrm{G}$ rings and $\mathrm{C}-\mathrm{O}$ stretching in $\mathrm{G}$ rings. It can be seen, by observing the change in the peak area in Figure 1, that the content of $G$ and $S$ units in EHL-SE is less, which may be related to the treatment method. Finally, peaks around $1035-1030 \mathrm{~cm}^{-1}$ can be attributed to the absorption of $\mathrm{C}-\mathrm{O}$ deformation in primary alcohol and aliphatic ether. It is well known that lignin contains hydroxyl groups and more ether linkages $(\mathrm{C}-\mathrm{O}-\mathrm{C})$. After steam explosion, accompanied by the detachment of hydroxyl groups and the breakage of ether bonds, signal peaks in EHL-SE are significantly weaker than EHL.

In general, the fundamental structure of lignin substrates has not undergone a distinct change by steam explosion. However, unit ratio of lignin (G, S, and H), hydroxyl content and alkyl content were partially different. Ether bonds in EHL also undergo obvious break during steam explosion, which may be responsible for the difference in the composition of pyrolysis products.

During lignin pyrolysis, aided by Py-GC/MS, gases, volatiles, and residue char were mainly produced [18]. This work only discussed volatile products that had boiling points below $500{ }^{\circ} \mathrm{C}$, which can be detected by GC/MS.

It could be seen from Figures 2 and 3 that signal peaks all appeared between $5 \mathrm{~min}$ and $25 \mathrm{~min}$. Meanwhile, as the temperature increased, peaks of pyrolysis products became more and more complex, and the type of compound also increased. Table 2 listed the number, compound, family and relative content at different temperatures. As can be seen from Table 2, there are 20 types of pyrolysis products, which contain ester, acid, ketone, aldehyde, sugar, imidazoline, pyrrole, pyridine, piperidine, indolizine, indole, furan, naphthenic, olefins, benzene, benzene derivative and phenolic compounds (G-, S-, $\mathrm{H}-$ and C-types). 


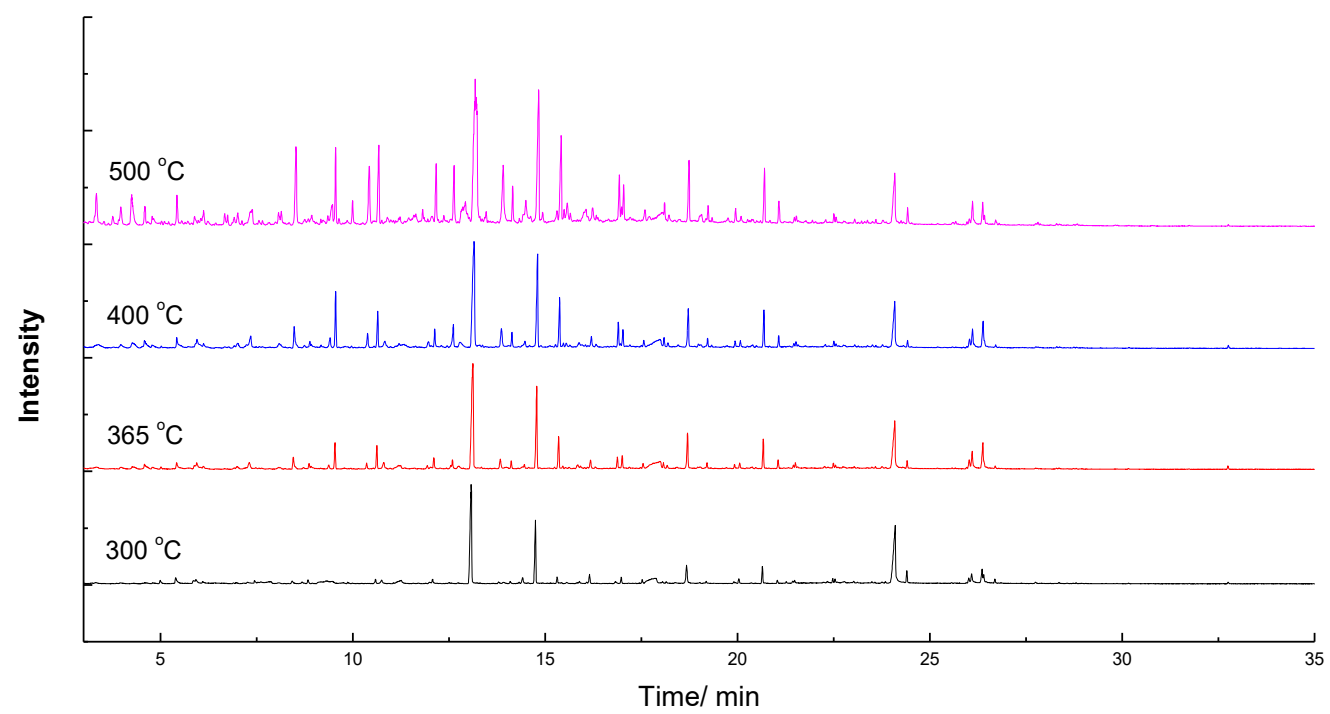

Figure 2. Gas Chromatography/Mass Spectrometry (GC/MS) diagram of EHL at different temperatures.

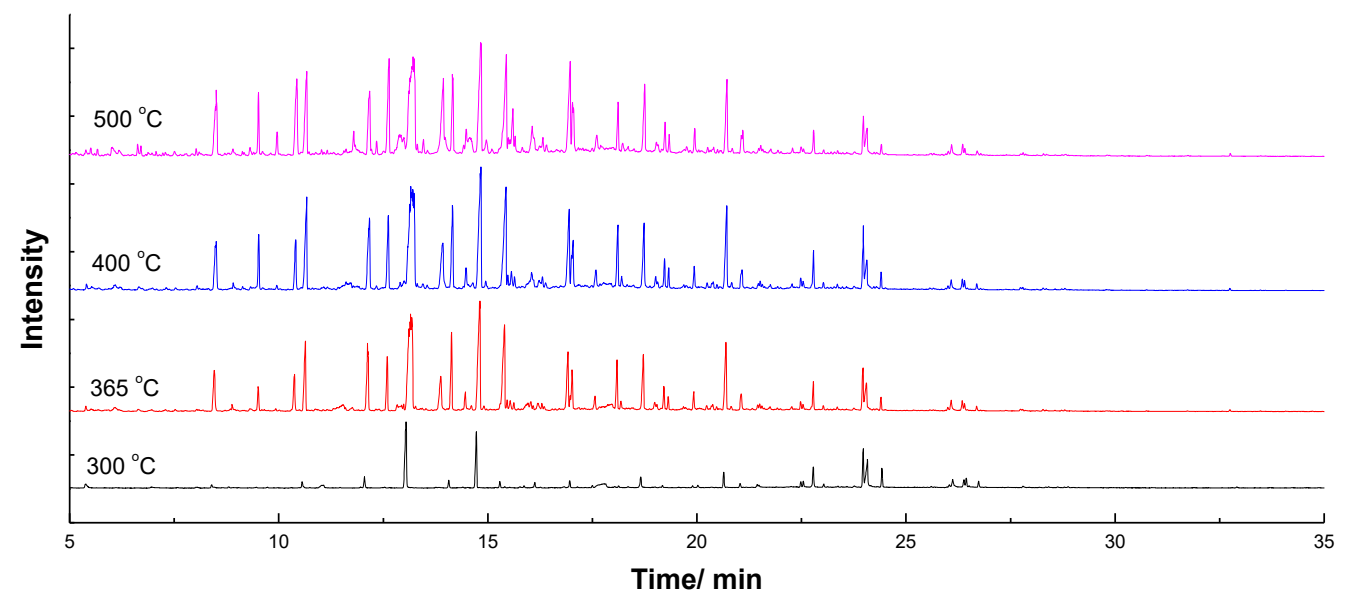

Figure 3. GC/MS diagram of EHL after steam explosion treatment at different temperatures.

By comparing the product lists of two lignin substrates (see Table 2), pyrolysis products of EHL were more abundant and complex. However, treated with steam explosion, lignin pyrolysis product distribution was more concentrated for phenolic compounds, and almost no heterocyclic compounds were formed. Sugars, furans, and olefins were also significantly less, and no alkane products were formed. It is worth noting that the content of benzene and benzene derivatives in EHL-SE pyrolysis products was increased, but when the temperature reaches $500^{\circ} \mathrm{C}$, the content of both was also reduced. Possible reason is that with higher temperature, primary pyrolytic products are gradually cleaved into other small molecular or gaseous products. Esters, acids, aldehydes and ketones in the product distribution also account for a certain proportion. Most of these products were long-chain acids or esters, similar to other studies [27], which were distributed in small amounts after the pyrolysis of lignin. As the temperature increases, the content of these products decreases. 
Table 2. Comparison of pyrolysis products of two raw materials at different temperatures.

\begin{tabular}{|c|c|c|c|c|c|c|c|c|}
\hline \multirow{3}{*}{ No } & \multirow{3}{*}{ Compound } & \multirow{3}{*}{ Family } & \multicolumn{6}{|c|}{ Relative Content/\% } \\
\hline & & & \multicolumn{2}{|c|}{$300^{\circ} \mathrm{C}$} & \multicolumn{2}{|c|}{$400^{\circ} \mathrm{C}$} & \multicolumn{2}{|c|}{$500^{\circ} \mathrm{C}$} \\
\hline & & & EHL & EHL-SE & EHL & EHL-SE & EHL & EHL-SE \\
\hline 1 & Methyl methacrylate & Ester & - & - & - & - & - & 1.310 \\
\hline 2 & Methylpyruvate & Ester & - & - & - & - & 0.721 & - \\
\hline 3 & Diisobutyl phthalate & Ester & - & 3.746 & - & 1.173 & - & 0.637 \\
\hline 4 & Dibutyl phthalate & Ester & - & 5.747 & - & 1.784 & - & 1.046 \\
\hline 5 & Ethyl palmitate & Ester & 1.328 & 3.058 & - & 0.470 & - & - \\
\hline 6 & Methylene succinic acid & Acid & - & 0.518 & - & - & - & - \\
\hline 7 & 2-Hydroxy-propionic acid & Acid & 0.685 & - & - & - & - & - \\
\hline 8 & Tetradecanoic acid & Acid & - & 0.502 & - & - & - & - \\
\hline 9 & Oleic acid & Acid & - & 0.459 & - & - & - & - \\
\hline 10 & N-hexadecanoic acid & Acid & 15.708 & 5.960 & 5.693 & 1.303 & 3.082 & 1.074 \\
\hline 11 & $\begin{array}{c}\text { Octadecene-9,12,15-trienoic } \\
\text { acid }\end{array}$ & Acid & 0.716 & - & 0.697 & - & - & - \\
\hline 12 & Anti-oleic acid & Acid & - & - & - & 0.414 & - & - \\
\hline 13 & Octadecanoic acid & Acid & 1.950 & 1.402 & 2.638 & - & 0.686 & - \\
\hline 14 & Hydroxyacetone & Ketone & - & - & 1.224 & - & - & - \\
\hline 15 & 1,2-Cyclopentanedione & Ketone & - & - & 1.447 & - & 1.488 & - \\
\hline 16 & $\begin{array}{l}\text { 2-Hydroxy-3-methyl-2- } \\
\text { cyclopenten-1-one }\end{array}$ & Ketone & - & - & 0.908 & - & - & - \\
\hline 17 & $\begin{array}{c}\text { 3-Methyl } \\
\text { cyclopentane-1,2-dione }\end{array}$ & Ketone & - & - & - & - & 0.997 & - \\
\hline 18 & 4(1H)-Pyridinone & Ketone & - & 1.801 & - & - & - & - \\
\hline 19 & 7-Hydroxy-pyrrolizin-1-one & Ketone & - & 0.368 & - & - & - & - \\
\hline 20 & Furfural & Aldehyde & 1.551 & 1.513 & 1.373 & - & - & - \\
\hline 21 & 5-Methylfurfural & Aldehyde & - & 0.390 & - & - & - & - \\
\hline 22 & $\mathrm{~N}$-valeraldehyde & Aldehyde & 0.793 & - & - & - & - & - \\
\hline 23 & 2,3-Anhydor-d-galactosan & Sugar & - & 0.340 & - & - & - & - \\
\hline 24 & Sedoheptulose anhydride & Sugar & - & - & - & 0.356 & - & - \\
\hline 25 & $\beta$-D-allose & Sugar & - & 4.067 & 2.832 & - & 1.125 & - \\
\hline 26 & 1,6-Anhydroglucopyranose & Sugar & 3.958 & - & - & - & - & - \\
\hline 27 & 2-Methyl-2-imidazoline & Imidazoline & - & - & 0.662 & - & - & - \\
\hline 28 & Pyrrole & Pyrrole & - & - & - & - & 1.006 & - \\
\hline 29 & 3-Methoxy pyridine & Pyridine & - & - & - & - & 0.639 & - \\
\hline 30 & 3-Hydroxypyridine & Pyridine & 1.774 & - & 0.707 & - & - & - \\
\hline 31 & N-methylpiperidine & Piperidine & - & - & 0.624 & - & - & - \\
\hline 32 & Indolizine & Indolizine & - & - & - & - & 1.662 & - \\
\hline 33 & 3-Methyl-indolizine & Indolizine & - & - & - & - & 1.048 & - \\
\hline 34 & Indole & Indole & - & - & - & 0.776 & - & 0.872 \\
\hline 35 & $\begin{array}{l}\text { 3-((piperidin-1-yl)methyl)- } \\
\text { 1H-indole }\end{array}$ & Indole & - & - & - & 1.276 & - & 1.527 \\
\hline 36 & 2,3-Dihydrobenzofuran & Furan & 19.075 & 17.029 & 14.684 & 13.944 & 13.869 & 11.503 \\
\hline 37 & $\begin{array}{l}\text { 1,2-Dimethyl-3-methylene } \\
\text {-cyclopropane }\end{array}$ & Naphthenic & - & - & 0.653 & - & - & - \\
\hline 38 & D-decadiene & Olefins & - & - & 3.671 & 1.795 & 2.088 & 1.460 \\
\hline 39 & 4,5-Nonadiene & Olefins & - & - & - & - & 1.013 & - \\
\hline 40 & $\begin{array}{l}\text { 6,6-Dimethyl-5-methylene-1,3 } \\
\text {-cyclopentadiene }\end{array}$ & Olefins & - & - & - & - & - & 0.667 \\
\hline
\end{tabular}


Table 2. Cont.

\begin{tabular}{|c|c|c|c|c|c|c|c|c|}
\hline \multirow{3}{*}{ No } & \multirow{3}{*}{ Compound } & \multirow{3}{*}{ Family } & \multicolumn{6}{|c|}{ Relative Content/\% } \\
\hline & & & \multicolumn{2}{|c|}{$300^{\circ} \mathrm{C}$} & \multicolumn{2}{|c|}{$400^{\circ} \mathrm{C}$} & \multicolumn{2}{|c|}{$500^{\circ} \mathrm{C}$} \\
\hline & & & EHL & EHL-SE & EHL & EHL-SE & EHL & EHL-SE \\
\hline 41 & $\begin{array}{l}\text { 5,5-Dimethyl-1-ethyl-1,3 } \\
\text {-cyclopentadiene }\end{array}$ & Olefins & 0.702 & - & - & - & - & - \\
\hline 42 & Toluene & Benzene & - & 1.119 & - & 1.262 & 2.227 & 1.865 \\
\hline 43 & $\begin{array}{l}\text { 3-Hydroxy-4-methoxy } \\
\text { benzaldehyde }\end{array}$ & $\begin{array}{l}\text { Benzene } \\
\text { derivative }\end{array}$ & - & - & - & - & 0.756 & - \\
\hline 44 & $\begin{array}{l}\text { 1-(3-hydroxy-4-methoxy } \\
\text { phenyl)-Ethanone }\end{array}$ & $\begin{array}{l}\text { Benzene } \\
\text { derivative }\end{array}$ & - & - & - & 0.781 & - & 0.650 \\
\hline 45 & 3,4-Dimethoxyacetophenone & $\begin{array}{l}\text { Benzene } \\
\text { derivative }\end{array}$ & - & 2.387 & - & 2.840 & - & - \\
\hline 46 & 3,5-Dimethoxyacetophenone & $\begin{array}{l}\text { Benzene } \\
\text { derivative }\end{array}$ & - & - & 2.433 & - & - & - \\
\hline 47 & $\begin{array}{l}\text { 1-(2,4,6-hydroxyphenyl)2 } \\
\text {-Pentanone }\end{array}$ & $\begin{array}{l}\text { Benzene } \\
\text { derivative }\end{array}$ & - & 0.587 & - & - & - & - \\
\hline 48 & 4-Ethyl-2-methoxyphenol & Phenol (G) & - & 1.340 & 0.893 & 3.544 & 1.081 & 2.578 \\
\hline 49 & 2-Methoxy-4-vinylphenol & Phenol (G) & - & 10.936 & - & 7.600 & - & 6.046 \\
\hline 50 & 4-Vinyl-2-methoxyphenol & Phenol (G) & 8.140 & - & 7.008 & - & 6.257 & - \\
\hline 51 & 2-Methoxyphenol & Phenol (G) & - & 1.262 & 2.299 & 4.352 & 3.130 & 3.863 \\
\hline 52 & 2,4-Dimethoxyphenol & Phenol (G) & - & - & - & - & - & 1.512 \\
\hline 53 & 2-Methoxy-4-methyl phenol & Phenol (G) & - & - & 1.980 & 3.075 & 2.126 & 3.735 \\
\hline 54 & Vanillin & Phenol (G) & 1.222 & 1.008 & 0.776 & 0.395 & - & - \\
\hline 55 & trans-Isoeugenol & Phenol (G) & 0.773 & 1.246 & 1.034 & 2.416 & 0.900 & 1.653 \\
\hline 56 & $\begin{array}{l}\text { 4-Hydroxy-3-methoxyaceto } \\
\text { phenone }\end{array}$ & Phenol (G) & - & 0.356 & - & - & - & - \\
\hline 57 & $\begin{array}{l}\text { 4-Hydroxy-3-methoxyprop } \\
\text { iophenone }\end{array}$ & Phenol (G) & - & - & - & 0.344 & - & - \\
\hline 58 & 2,6-Dimethoxy-phenol & Phenol (S) & 0.777 & 1.033 & 3.217 & 5.823 & 3.416 & 5.003 \\
\hline 59 & $\begin{array}{l}\text { 2,6-Dimethoxy-phenol } \\
\text { acetate }\end{array}$ & Phenol (S) & - & - & - & 0.489 & - & 1.419 \\
\hline 60 & $\begin{array}{l}\text { 3,5-Dimethoxy-4-hydroxy } \\
\text { phenylacetic acid }\end{array}$ & Phenol (S) & - & - & - & 0.549 & - & - \\
\hline 61 & $\begin{array}{l}\text { 4-Hydroxy-3,5-dimethoxy- } \\
\text { benzaldehyde }\end{array}$ & Phenol (S) & - & 0.454 & - & - & - & - \\
\hline 62 & 4-Allyl-2,6-dimethoxyphenol & Phenol (S) & 1.921 & 3.018 & - & 5.381 & 1.858 & 4.174 \\
\hline 63 & $\begin{array}{l}\text { 4-Hydroxy-3,5-dimethoxy } \\
\text { acetophenone }\end{array}$ & Phenol (S) & - & 0.782 & 0.753 & 0.925 & - & 0.584 \\
\hline 64 & Phenol & Phenol $(\mathrm{H})$ & - & 0.655 & 2.108 & 2.894 & 3.655 & 3.315 \\
\hline 65 & 2-Methylphenol & Phenol $(\mathrm{H})$ & - & - & - & - & 0.835 & 0.724 \\
\hline 66 & 4-Methylphenol & Phenol $(\mathrm{H})$ & - & - & 1.189 & 2.044 & 2.519 & 3.479 \\
\hline 67 & 4-Ethylphenol & Phenol $(\mathrm{H})$ & - & 2.032 & 1.217 & 3.976 & 1.997 & 2.892 \\
\hline 68 & 3-Methoxy-5-methylphenol & Phenol $(\mathrm{H})$ & - & - & - & - & - & 0.574 \\
\hline 69 & 3,4-Dimethoxy-phenol & Phenol $(\mathrm{H})$ & - & - & - & - & 0.683 & - \\
\hline 70 & 5-Tert-butyl pyrogallol & Phenol $(\mathrm{H})$ & - & - & - & - & - & 2.542 \\
\hline 71 & $\begin{array}{c}\text { Methyl } \mathrm{p} \\
\text { hydroxyphenylpropionate }\end{array}$ & Phenol $(\mathrm{H})$ & - & - & - & 0.426 & - & - \\
\hline 72 & Catechol & Phenol (C) & - & - & 0.989 & 0.483 & 2.519 & 2.400 \\
\hline 73 & 3-Methoxycatechol & Phenol (C) & - & - & 1.863 & 3.151 & 3.347 & 4.000 \\
\hline 74 & 4-Methylcatechol & Phenol (C) & - & - & - & - & - & 1.777 \\
\hline
\end{tabular}


All pyrolysis products were listed in Table 2, which could be roughly classified into two categories: lignin derivatives and carbohydrate derivatives. Lignin derivatives mainly contained phenolic compounds, benzene derivatives and benzene. The possible reason for presence of carbohydrate derivatives was that cellulose and hemicellulose were not completely removed during the enzymatic hydrolysis of feedstock, resulting in feedstock containing a small portion of cellulose or hemicellulose (about $5 \mathrm{wt}-10 \mathrm{wt} \%$ ) [28]. Due to the cleavage of bonds between lignin and polysaccharide, a certain amount of carbohydrate derivatives could also be partially formed [29].

Total product distribution, obtained by the pyrolysis of EHL, with or without steam explosion, is shown in Figure 4. Phenolic compounds which linked with phenolic hydroxyl and methoxyl groups [17] were the main substances in pyrolysis products obtained by two lignin substrates. Some researchers divided phenolic compounds into four categories: guaiacol (G), syringol (S), phenol (H) and catechol (C) $[27,30]$. Among them, G-type phenol was predominant group compared to other types because guaiacyl unit was the predominant unit in lignin [30]. Furthermore, G-type phenols could be produced by the break of $\beta-\mathrm{O}-4$ bonds, which need the lowest energy of all kinds of bonds [31]. It was noticeable that 2-methoxy-4-vinylphenol with an $11 \%$ relative content was the most predominant pyrolytic product for lignin after steam explosion treatment. Meanwhile, carbohydrate derivatives mainly included sugar, such as 2,3-anhydor-d-galactosan, sedoheptulose anhydride, $\beta$-d-allose and 1,6-anhydroglucopyranose, which originated from the pyrolysis of cellulose and hemicellulose [20]. Among them, $\beta$-d-allose was monosaccharide, which was formed by thermal degradation of hemicellulose [32]. It is worth noting that $\beta$-d-allose showed high content at higher temperature, and its stability was higher than other carbohydrate derivatives, which was also observed by other researchers [30]. There were other carbohydrate derivatives released, such as furan, ketone, acid, ester, and aldehyde, which was consistent with the reference results. It is worth mentioning that furan substance (2,3-dihydrobenzofuran) was directly derived from the secondary reaction of cellulose [33,34]. Pyrolysis of cellulose or hemicellulose produced naphthenic, such as 1,2-dimethyl-3-methylene-cyclopropane. Meanwhile, the secondary dehydration of cellulose or hemicellulose produced olefins [20], including decadiene, 4,5-nonadiene, 6,6-dimethyl-5-methylene-1,3-cyclopentadiene and 5,5-dimethyl-1-ethyl-1,3-cyclopentadiene.

Spurred by two competing reactions in the pyrolysis of cellulose and hemicellulose, one was the cleavage of glycosidic bonds to form various monosaccharides, and the other was ring opening reactions of furan and cleavage of $\mathrm{C}-\mathrm{C}$ bonds to form small molecules [35]. Some macromolecules were also found, such as ester, acid, ketone and aldehyde, which was similar to the experimental result of other researches [24]. The appearance of nitrogen-containing substances, containing imidazoline, pyrrole, pyridine, piperidine, indolizine and indole were mainly due to the secondary decomposition of volatile substances [32].

The specific phenolic substance distribution was shown in Figure 5. The main products after pyrolysis of the raw material were phenolic compounds. The pyrolysis of lignin resulted in the cleavage of alkyl chain, thereby producing G-type, H-type, S-type and C-type products. After steam explosion treatment, the relative content of phenolic substances all increased significantly. Due to demethylation or demethoxylation on aromatic rings, the formation of G-type and S-type products could happen. Furthermore, as those reactions continued, H-type and C-type products were also produced. As the temperature increased, the yield of G-type and S-type products first increased and then decreased, while the yield of H-type and C-type products continued to increase. The reason may be that pyrolysis of raw materials was not sufficient at lower temperature, large number of methoxyl groups still linked on the phenol which led to the higher content of S-type phenols (containing two methoxyl groups) and G-type phenols (containing one methoxyl group) [36]. As temperature continued to rise, more methoxyl groups would fall off the phenol and transfer into $\mathrm{CH}_{4}[9,37]$. Therefore, the content of H-type and C-type products obviously increased. 


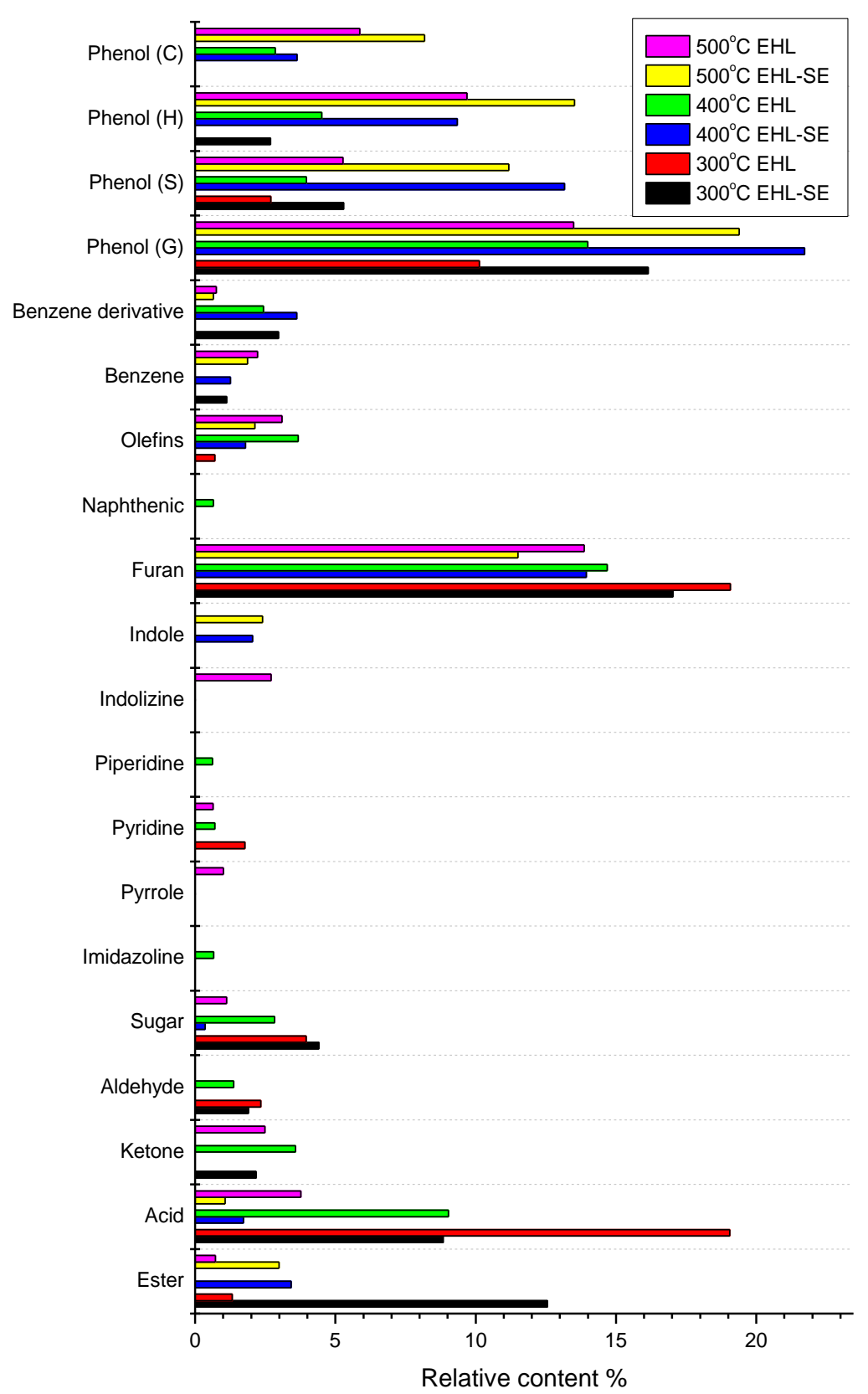

Figure 4. Total product distribution obtained by pyrolysis of EHL and EHL-SE with different temperatures.

The formation of phenolic products containing unsaturated side chains was more prone to occur than products containing saturated side chains at lower temperatures, such as 2-methoxy-4-vinylphenol, which are consistent with other reports [4]. However, the result of phenolic compounds containing allyl groups in side chains were reversed, the content of which was higher at high temperatures, such as trans-isoeugenol and 4-allyl-2,6-dimethoxyphenol. Products containing 1-carbon side chain (1-C), such as 2-methylphenol, 4-methylphenol, 2,4-dimethoxy-phenol, 2-methoxy-4-methylphenol, 3-methoxycatechol, 4-methylcatechol, 3-methoxy-5-methylphenol and 3,4-dimethoxy-phenol, had the maximum content at high temperatures, which was explained by secondary pyrolysis reactions of $C-C$ bond in the literature [38]. Meanwhile, these products could also be formed due to the break of $\beta-1$ and $\beta-5$ bonds in EHL or EHL-SE [39,40]. There were also some benzene and benzene derivatives, 
which may be produced by the rearrangement reactions or oxidation reactions that occurred during lignin depolymerization [20].

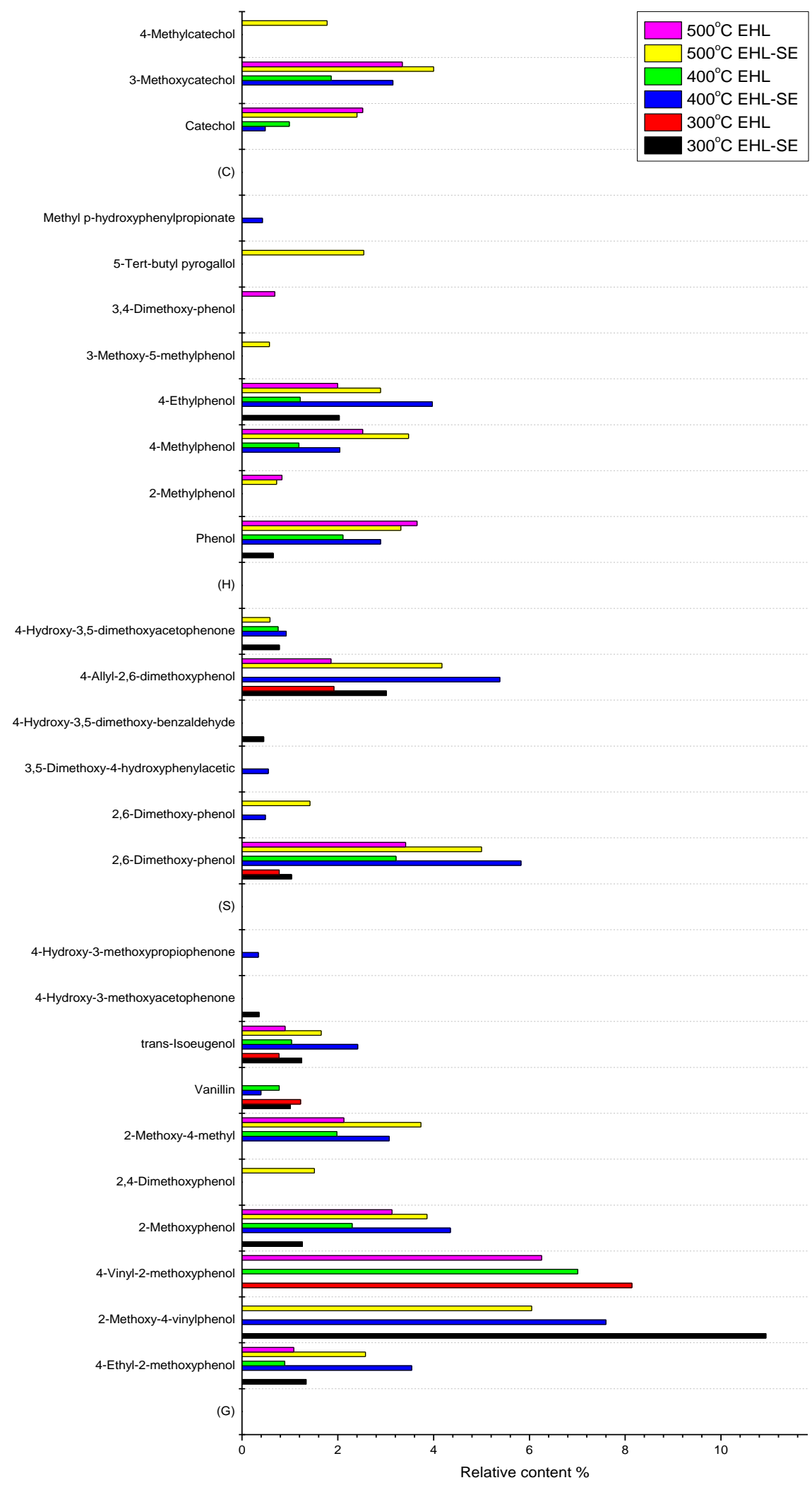

Figure 5. Total product distribution of phenolic compounds obtained by pyrolysis of EHL and EHL-SE with different temperatures. 
Several chemical methods have been applied to measure S/G in lignin, such as Fourier transformed infrared spectroscopy (FTIR) and solid-state ${ }^{13} \mathrm{C}$ NMR. However, as there is insufficient sensitivity and poor resolution in the spectra, it is difficult to determine $\mathrm{S} / \mathrm{G}$ ratio in lignin by the analytical methods above [11]. Pyrolysis-gas chromatography/mass spectroscopy (Py-GC/MS) is a sensitive method for characterizing the structure of lignin, which also can provide useful information concerning the structure of lignin [11]. From the data in Table 3, it can be found that the content of each type unit in the substrates changed with the treatment methods. After steam explosion, the content of each type phenolic unit increased, and the $S / G$ ratio also increased. As temperature increased, $S / G$ ratio in EHL-SE reached the maximum at $400{ }^{\circ} \mathrm{C}$. It was indicated that steam explosion had a great influence on the proportion of the unit in lignin pyrolytic substrates.

Table 3. Proportion of G, S, H and C of pyrolysis products of different samples and S/G ratio determined with Py-GC/MS.

\begin{tabular}{cccccc}
\hline Sample & G wt $\%$ & S wt $\%$ & H wt $\%$ & C wt $\%$ & S/G Ratio \\
\hline EHL $\left(300^{\circ} \mathrm{C}\right)$ & 10.135 & 2.698 & 0.000 & 0.000 & 0.266 \\
EHL-SE $\left(300^{\circ} \mathrm{C}\right)$ & 16.148 & 5.287 & 2.687 & 0.000 & 0.327 \\
EHL $\left(400^{\circ} \mathrm{C}\right)$ & 13.990 & 3.970 & 4.514 & 2.852 & 0.284 \\
EHL-SE $\left(400^{\circ} \mathrm{C}\right)$ & 21.726 & 13.167 & 9.340 & 3.634 & 0.606 \\
EHL $\left(500^{\circ} \mathrm{C}\right)$ & 13.494 & 5.274 & 9.689 & 5.866 & 0.391 \\
EHL-SE $\left(500^{\circ} \mathrm{C}\right)$ & 19.387 & 11.180 & 13.526 & 8.177 & 0.577 \\
\hline
\end{tabular}

\section{Materials and Methods}

\subsection{Materials}

EHL mentioned in this experiment was provided by Department of Bioengineering, Nanjing Forestry University, China. Specific treatment steps of steam explosion of enzymatic hydrolysis of lignin referred to the research of our previous report [41].

\subsection{Analysis of EHL and EHL-SE}

Proximate analysis, containing moisture, ash, volatile matter and fixed carbon, was performed according to American Society of Testing Materials (ASTM) standard. Elemental analysis of lignin, including carbon, nitrogen and hydrogen, oxygen percentage for lignin was measured with PerkinElmer Series II 2400 Analyzer (PerkinElmer, Waltham, MA, USA). Each sample was analyzed three times and all analysis results are shown in Table 4.

Table 4. Proximate and ultimate analysis of EHL and EHL-SE.

\begin{tabular}{|c|c|c|c|c|c|}
\hline Proximate Analysis ${ }^{a}$ wt $\%$ & EHL & EHL-SE & Ultimate Analysis ${ }^{b} w \%$ & EHL & EHL-SE \\
\hline Moisture & 1.40 & 3.50 & Carbon & 51.51 & 39.93 \\
\hline Ash & 5.10 & 3.70 & Hydrogen & 4.74 & 3.83 \\
\hline Volatile matter & 70.15 & 75.23 & Nitrogen & 2.45 & 0.83 \\
\hline Fixed carbon $^{\mathrm{c}}$ & 23.35 & 17.57 & Oxygen $^{c}$ & 41.30 & 55.41 \\
\hline
\end{tabular}

${ }^{a}$ On dry basis. ${ }^{b}$ Ash and moisture free ${ }^{\mathrm{c}}$ Estimated by difference.

\subsection{Characterization}

Fourier transform infrared (FTIR) spectra of EHL and EHL-SE were recorded by a Nicolet 6700 FTIR spectrometer (Thermo Electron, Waltham, MA, USA) under the resolution of $1 \mathrm{~cm}^{-1}$ in 32 scans by a KBr disk with the wavenumber ranging from 4000 to $500 \mathrm{~cm}^{-1}$. Pyrolysis experiment of EHL was conducted using pyrolyzer (CDS 5250, Chemical Data Systems, CDS Analytical LLC, Oxford, PA, USA) with a direct connection to gas chromatography (GC) coupled with a mass spectrometer (MS, 
Trace DSQ II, Thermo Fisher Scientific, Waltham, MA, USA). In each experiment, $0.5 \mathrm{mg}$ sample was placed in quartz packing tube. The pyrolysis temperature was set from room temperature to 300,365 (maximum weight loss peak temperature of lignin), 400 , and $500^{\circ} \mathrm{C}$ with heating rate of $20^{\circ} \mathrm{C} / \mathrm{min}$. Then the volatiles were analyzed by GC/MS (Thermo Fisher Scientific, Waltham, MA, USA). Injector temperature were kept at $300{ }^{\circ} \mathrm{C}$. The chromatographic separation was performed using TR-5MS capillary column $(30 \mathrm{~m} \times 0.25 \mathrm{~mm}$ i.d., $0.25 \mu \mathrm{m}$ film thickness). High purity nitrogen $(99.999 \%)$ was used as the carrier gas with a constant flow rate of $40 \mathrm{~mL} / \mathrm{min}$. The identification of chromatographic peaks was achieved according to the NIST library and the relevant literature.

\section{Conclusions}

This paper mainly explored the distribution of pyrolysis products of EHL and EHL-SE. FTIR results showed that the intensity of signal peaks of the hydroxyl group, alkyl group and other groups in EHL changed after steam explosion treatment. Py-GC/MS results showed that phenolic compounds were main substances in pyrolysis products, and the unit content $(\mathrm{G}, \mathrm{S}$ and $\mathrm{H})$ in phenolic compounds also occurred with different treatment methods and pyrolysis temperatures. Pyrolysis products in EHL-SE were more concentrated, producing more phenolic compounds. When temperature was continuously increased, the content of G-type and S-type unit increased first and then decreased, and the content of H-type and C-type unit continuously increased, which was related to the demethoxylation reaction. Furthermore, $\mathrm{S} / \mathrm{G}$ ratio had also changed, which had reached a maximum value at $400{ }^{\circ} \mathrm{C}$ in EHL-SE. The most predominant pyrolytic product for lignin after steam explosion treatment was 2-methoxy-4-vinylphenol with $11 \%$ relative content.

Author Contributions: Y.D. and X.L. contributed equally. Y.D. and X.L. carried out literature search, data collection, data analysis. C.H., L.L., and Q.H. carried out data collection, data analysis. D.W. carried out data collection and figures drawing. C.X. did data interpretation and wrote the manuscript. X.G. designed the framework and wrote the manuscript. All authors discussed the results and contributed to the final manuscript. All authors have read and agreed to the published version of the manuscript.

Funding: This research was funded by the National Natural Science Foundation of China (no. 21774059), the Priority Academic Program Development (PAPD) of Jiangsu Higher Education Institutions, the opening funding of Jiangsu Key Lab of Biomass based Green Fuels and Chemicals, and College Students' Practice and Innovation Training Project (201810298058Z, 201910298190E, 201910298011Z, 201910298052Z).

Conflicts of Interest: The authors declare no competing financial interest.

\section{References}

1. Ragauskas, A.J.; Beckham, G.T.; Biddy, M.J.; Chandra, R.; Chen, F.; Davis, M.F.; Davison, B.H.; Dixon, R.A.; Gilna, P.; Keller, M.; et al. Lignin Valorization: Improving Lignin Processing in the Biorefinery. Science 2014, 344, 1246843. [CrossRef] [PubMed]

2. Azadi, P.; Inderwildi, O.R.; Farnood, R.; King, D.A. Liquid fuels, hydrogen and chemicals from lignin: A critical review. Renew. Sust. Energy Rev. 2013, 21, 506-523. [CrossRef]

3. Kang, S.M.; Li, X.L.; Fan, J.; Chang, J. Hydrothermal conversion of lignin: A review. Renew. Sust. Energy Rev. 2013, 27, 546-558. [CrossRef]

4. Collard, F.-X.; Blin, J. A review on pyrolysis of biomass constituents: Mechanisms and composition of the products obtained from the conversion of cellulose, hemicelluloses and lignin. Renew. Sust. Energy Rev. 2014, 38, 594-608. [CrossRef]

5. Wang, S.; Lin, H.; Ru, B.; Sun, W.; Wang, Y.; Luo, Z. Comparison of the pyrolysis behavior of pyrolytic lignin and milled wood lignin by using TG-FTIR analysis. J. Anal. Appl. Pyrolysis 2014, 108, 78-85. [CrossRef]

6. Joffres, B.; Laurenti, D.; Charon, N.; Daudin, A.; Quignard, A.; Geantet, C. Thermochemical Conversion of Lignin for Fuels and Chemicals: A Review. Oil Gas Sci. Technol. 2013, 68, 753-763. [CrossRef]

7. Pandey, M.P.; Kim, C.S. Lignin Depolymerization and Conversion: A Review of Thermochemical Methods. Chem. Eng. Technol. 2011, 34, 29-41. [CrossRef]

8. Kim, J.-S. Production, separation and applications of phenolic-rich bio-oil-A review. Bioresour. Technol. 2015, 178, 90-98. [CrossRef] 
9. Shen, D.; Liu, G.; Zhao, J.; Xue, J.; Guan, S.; Xiao, R. Thermo-chemical conversion of lignin to aromatic compounds: Effect of lignin source and reaction temperature. J. Anal. Appl. Pyrolysis 2015, 112, 56-65. [CrossRef]

10. Mattonai, M.; Licursi, D.; Antonetti,C.; Galletti, A.M.R.; Ribechini, E. Py-GC/MS and HPLC-DAD characterization of hazelnut shell and cuticle: Insights into possible re-evaluation of waste biomass. J. Anal. Appl. Pyrolysis 2017, 127, 321-328. [CrossRef]

11. Sequeiros, A.; Labidi, J. Characterization and determination of the $\mathrm{S} / \mathrm{G}$ ratio via Py-GC/MS of agricultural and industrial residues. Ind. Crop. Prod. 2017, 97, 469-476. [CrossRef]

12. Ohra-aho, T.; Gomes, F.J.B.; Colodette, J.L.; Tamminen, T. S/G ratio and lignin structure among Eucalyptus hybrids determined by Py-GC/MS and nitrobenzene oxidation. J. Anal. Appl. Pyrolysis 2013, 101, 166-171. [CrossRef]

13. Gao, N.; Li, A.; Quan, C.; Du, L.; Duan, Y. TG-FTIR and Py-GC/MS analysis on pyrolysis and combustion of pine sawdust. J. Anal. Appl. Pyrolysis 2013, 100, 26-32. [CrossRef]

14. Gu, X.; Ma, X.; Li, L.; Liu, C.; Cheng, K.; Li, Z. Pyrolysis of poplar wood sawdust by TG-FTIR and Py-GC/MS. J. Anal. Appl. Pyrolysis 2013, 102, 16-23. [CrossRef]

15. Mullen, C.A.; Boateng, A.A. Catalytic pyrolysis-GC/MS of lignin from several sources. Fuel Process. Technol. 2010, 91, 1446-1458. [CrossRef]

16. Lou, R.; Wu, S.; Lyu, G. Quantified monophenols in the bio-oil derived from lignin fast pyrolysis. J. Anal. Appl. Pyrolysis 2015, 111, 27-32. [CrossRef]

17. Ma, Z.; Sun, Q.; Ye, J.; Yao, Q.; Zhao, C. Study on the thermal degradation behaviors and kinetics of alkali lignin for production of phenolic-rich bio-oil using TGA-FTIR and Py-GC/MS. J. Anal. Appl. Pyrolysis 2016, 117, 116-124. [CrossRef]

18. Zhang, M.; Resende, F.L.P.; Moutsoglou, A. Catalytic fast pyrolysis of aspen lignin via Py-GC/MS. Fuel 2014, 116, 358-369. [CrossRef]

19. Chen, D.; Wang, Y.; Liu, Y.; Cen, K.; Cao, X.; Ma, Z.; Li, Y. Comparative study on the pyrolysis behaviors of rice straw under different washing pretreatments of water, acid solution, and aqueous phase bio-oil by using TG-FTIR and Py-GC/MS. Fuel 2019, 252, 1-9. [CrossRef]

20. Mattonai, M.; Watanabe, A.; Shiono, A.; Ribechini, E. Degradation of wood by UV light: A study by EGA-MS and Py-GC/MS with on line irradiation system. J. Anal. Appl. Pyrolysis 2019, 139, 224-232. [CrossRef]

21. Mattonai, M.; Ribechini, E. Fast screening for hydrolysable and condensed tannins in lignocellulosic biomass using reactive Py-GC/MS with in situ silylation. J. Anal. Appl. Pyrolysis 2018, 135, 242-250. [CrossRef]

22. Chen, L.; Wang, X.; Yang, H.; Lu, Q.; Li, D.; Yang, Q.; Chen, H. Study on pyrolysis behaviors of non-woody lignins with TG-FTIR and Py-GC/MS. J. Anal. Appl. Pyrolysis 2015, 113, 499-507. [CrossRef]

23. Zhang, M.; Resende, F.L.P.; Moutsoglou, A.; Raynie, D.E. Pyrolysis of lignin extracted from prairie cordgrass, aspen, and Kraft lignin by Py-GC/MS and TGA/FTIR. J. Anal. Appl. Pyrolysis 2012, 98, 65-71. [CrossRef]

24. Liu, Q.; Wang, S.; Zheng, Y.; Luo, Z.; Cen, K. Mechanism study of wood lignin pyrolysis by using TG-FTIR analysis. J. Anal. Appl. Pyrolysis 2008, 82, 170-177. [CrossRef]

25. Zhou, H.; Meng, A.; Long, Y.; Li, Q.; Zhang, Y. Interactions of municipal solid waste components during pyrolysis: A TG-FTIR study. J. Anal. Appl. Pyrolysis 2014, 108, 19-25. [CrossRef]

26. Meng, A.; Zhou, H.; Qin, L.; Zhang, Y.; Li, Q. Quantitative and kinetic TG-FTIR investigation on three kinds of biomass pyrolysis. J. Anal. Appl. Pyrolysis 2013, 104, 28-37. [CrossRef]

27. Brebu, M.; Tamminen, T.; Spiridon, I. Thermal degradation of various lignins by TG-MS/FTIR and Py-GC-MS. J. Anal. Appl. Pyrolysis 2013, 104, 531-539. [CrossRef]

28. Consolación, Á.; Francisco, M.R.; Bruno, D. Enzymatic hydrolysis of biomass from wood. Microb. Biotechnol. 2016, 9, 149-156.

29. Martinez, M.G.; Ohra-aho, T.; Perez, D.d.S.; Tamminen, T.; Dupont, C. Influence of step duration in fractionated Py-GC/MS of lignocellulosic biomass. J. Anal. Appl. Pyrolysis 2019, 137, 195-202. [CrossRef]

30. Wang, S.; Ru, B.; Lin, H.; Sun, W.; Luo, Z. Pyrolysis behaviors of four lignin polymers isolated from the same pine wood. Bioresour. Technol. 2015, 182, 120-127. [CrossRef]

31. Diehl, B.G.; Brown, N.R.; Frantz, C.W.; Lumadue, M.R.; Cannon, F. Effects of pyrolysis temperature on the chemical composition of refined softwood and hardwood lignins. Carbon 2013, 60, 531-537. [CrossRef]

32. Ma, W.; Rajput, G.; Pan, M.; Lin, F.; Zhong, L.; Chen, G. Pyrolysis of typical MSW components by Py-GC/MS and TG-FTIR. Fuel 2019, 251, 693-708. [CrossRef] 
33. Paulsen, A.D.; Mettler, M.S.; Dauenhauer, P.J. The Role of Sample Dimension and Temperature in Cellulose Pyrolysis. Energy Fuels 2013, 27, 2126-2134. [CrossRef]

34. Zhou, S.; Pecha, B.; van Kuppevelt, M.; McDonald, A.G.; Garcia-Perez, M. Slow and fast pyrolysis of Douglas-fir lignin: Importance of liquid-intermediate formation on the distribution of products. Biomass Bioenergy 2014, 66, 398-409. [CrossRef]

35. Chen, S.; Meng, A.; Long, Y.; Zhou, H.; Li, Q.; Zhang, Y. TGA pyrolysis and gasification of combustible municipal solid waste. J. Energy. Inst. 2015, 88, 332-343. [CrossRef]

36. Asmadi, M.; Kawamoto, H.; Saka, S. Thermal reactions of guaiacol and syringol as lignin model aromatic nuclei. J. Anal. Appl. Pyrolysis 2011, 92, 88-98. [CrossRef]

37. Lou, R.; Wu, S.; Lv, G. Fast pyrolysis of enzymatic/mild acidolysis lignin from moso bamboo. Bioresources 2010, 5, 827-837.

38. Kawamoto, H. Lignin pyrolysis reactions. J. Wood Sci. 2017, 63, 117-132. [CrossRef]

39. Kuroda, K.; Nakagawa-izumi, A. Analytical pyrolysis of lignin: Products stemming from beta-5 substructures. Org. Geochem. 2006, 37, 665-673. [CrossRef]

40. Kuroda, K.; Ashitani, T.; Fujita, K.; Hattori, T. Thermal behavior of beta-1 subunits in lignin: Pyrolysis of 1,2-diarylpropane-1,3-diol-type lignin model compounds. J. Agric. Food. Chem. 2007, 55, 2770-2778. [CrossRef]

41. Wu, Z.; Zhu, X.; Guo, H.; Jiang, Y.; Gu, X. A kinetic study of lignin pyrolysis over base catalyst during steam exploded depolymerization. Catal. Today 2019, 327, 226-234. [CrossRef]

(C) 2020 by the authors. Licensee MDPI, Basel, Switzerland. This article is an open access article distributed under the terms and conditions of the Creative Commons Attribution (CC BY) license (http://creativecommons.org/licenses/by/4.0/). 